\title{
Association of Histopathological Markers with Clinico- Pathological Factors in Mexican Women with Breast Cancer
}

\author{
Bandala Cindy ${ }^{1}$, De la Garza-Montaño Paloma ${ }^{1}$, Cortés-Algara Alfredo ${ }^{2}$, Cruz- \\ López Jaime ${ }^{3}$, Domínguez-Rubio Rene ${ }^{2}$, González-López Nelly Judith ${ }^{4}$, Cárdenas- \\ Rodríguez Noemi ${ }^{5}$, Alfaro-Rodríguez $\mathbf{A}^{1}$, Salcedo $\mathbf{M}^{6}$, Floriano-Sanchez $\mathbf{E}^{3}$, \\ Lara-Padilla Eleazar ${ }^{2 *}$
}

\begin{abstract}
Background: Breast cancer (BCa) is the most common malignancy in Mexican women. A set of histopathological markers has been established to guide $\mathrm{BCa}$ diagnosis, prognosis and treatment. Nevertheless, in only a few Mexican health services, such as that of the Secretariat of National Defense (SEDENA for its acronym in Spanish), are these markers commonly employed for assessing $\mathrm{BCa}$. The aim of this study was to explore the association of Ki67, TP53, HER2/neu, estrogenic receptors (ERs) and progesterone receptors (PRs) with BCa risk factors. Materials and Methods: Clinical histories provided background patient information. Immunohistochemical (IHC) analysis was conducted on 48 tissue samples from women diagnosed with $\mathrm{BCa}$ and treated with radical mastectomy. The Chi square test or Fisher exact test together with the Pearson and Spearman correlation were applied. Results: On average, patients were $58 \pm 10.4$ years old. It was most common to find invasive ductal carcinoma (95.8\%), histological grade 3 (45.8\%), with a poor Nottingham Prognostic Index (NPI; 80.4\%). ERs and PRs were associated with smoking and alcohol consumption, metastasis at diagnosis and Ki67 expression $(p<0.05)$. PR+ was also related to urea and ER+ $(\mathbf{p}<0.05)$. Ki67 was associated with TP53 and elevated triglycerides $(p<0.05)$, and HER2/neu with $E R+$, the number of pregnancies and tumor size $(p<0.05)$. TP53 was also associated with a poor NPI $(\mathbf{p}<0.05)$ and CD34 with smoking $(\mathbf{p}<0.05)$. The triple negative status (ER-/PR-/HER2/neu-) was related to smoking, alcohol consumption, exposure to biomass, number of pregnancies, metastasis and a poor NPI $(p<0.05)$. Moreover, the luminal B subtype was associated with histological type $(p=0.007)$, tumor size ( $p=0.03$ ) and high cholesterol ( $p=0.02)$. Conclusions: Ki67, TP53, HER2/neu, ER and PR proved to be related to several clinical and pathological factors. Hence, it is crucial to determine this IHC profile in women at risk for BCa. Certain associations require further study to understand physiological/biochemical/molecular processes.
\end{abstract}

Keywords: BCA - Ki67 - TP53 - HER2/neu - estrogenic receptor - progesterone receptor - Mexican women

Asian Pac J Cancer Prev, 16 (18), 8397-8403

\section{Introduction}

Breast cancer $(\mathrm{BCa})$ had an incidence of 1.8 million cases worldwide in 2013 , representing a sizeable percentage of the 13.1 million cases of malignancies. It was the second leading cause of cancer deaths for women globally $(464,000)$ and the first cause of disability-adjusted life years (DALYs). The total deaths, 63\% occur in developing and $37 \%$ in developed countries (Fitzmaurice et al., 2015). BCa incidence has increased steadily in the last few years in Mexico (DGIS/SINAIS, 2010; Bandala et al., 2012; Anaya-Ruiz et al., 2014).

$\mathrm{BCa}$ has been the leading cause of mortality from malignant neoplasms in Mexican women since 2006 (Chavarri-Guerra et al., 2012; Justo et al., 2013; PerezSantos and Anaya-Ruiz 2013). Several reports have shown that the risk factors of $\mathrm{BCa}$ are related to demography, socio-economic status, genetics, lifestyle and reproductive behavior, among other factors (Tirona et al., 2010; Justo et al., 2013).

Besides using histological classification, $\mathrm{BCa}$ has been typed by immunohistochemistry (IHC) expression of estrogenic receptors (ERs), progesterone receptors (PRs) and human epidermal receptor 2 (HER2/neu), also known as ErbB2. Seshie et al. (2015) categorized this expression as luminal $\mathrm{A}(\mathrm{ER} / \mathrm{PR}+, \mathrm{HER} 2 /$ neu- $)$, luminal B (ER/PR+,

${ }^{1}$ Division of Neuroscience. National Institute of Rehabilitation, SSA, ${ }^{2}$ Laboratory of Molecular Oncology and Oxidative Stress, Superior Medicine School of National Polytechnic Institute, Mexico City, ${ }^{3}$ Military School of Graduate of Health, SEDENA, ${ }^{4}$ Gynecology Hospital No. 3, Medical Center "La Raza”. IMSS, ${ }^{5}$ Laboratory of Neurosciences (Neurochemistry), National Institute of Pediatrics, SSA, ${ }^{6}$ Unidad de Investigación Medica en Enfermedades Oncológicas, National Center Medical "Siglo XXI”, IMSS, Mexico *For correspondence: elarapa@hotmail.com 
HER2/neu+), non-luminal (ER-/PR-, HER2/neu+) and triple negative (ER-/PR-/HER2/neu-).

Several markers have been associated with $\mathrm{BCa}$ patient prognosis. For instance, the nuclear proliferation marker Ki67 is used to predict response to chemotherapy (Azambuja et al., 2007; Cheang et al., 2009; Yerushalmi et al., 2010; Cuzick et al., 2011; Niikura et al., 2012; Ohno et al., 2013; Von Minckwitz et al., 2013; Shui et al., 2015). CD34, a useful angiogenesis marker, is a transmembrane glycoprotein whose expression is associated with hematopoietic precursors and capillary endothelial cells. The identification of microvessels using CD34 immunohistochemistry can help to identify the most aggressive breast tumors (Hsiao et al., 2010; Maschio et al., 2014). Moreover, alteration of the tumor suppressor gene p53 (also known as TP53) is considered to be a critical step in the development of many human cancers (Lane et al., 1992; Frebourg et al., 1993). Changes in this gene have been detected in a wide range of human tumors including BCa (Nigro et al., 1989). BCa research has focused on patients with primary, node-negative breast disease, and alterations in the p53 gene have been associated with poor prognosis (Thor et al., 1992; Elledge et al., 1993; Thorlacius et al., 1993).

The expression of tumor-specific proteins in mammary glands may be critical to BCa development and the success of chemotherapy treatment (Bandala et al., 2012). Some of these markers have been related to histological grade (Ji et al., 2014; Petric et al., 2014), metastasis (Bandala et al., 2012), lifestyle (León-Hernández et al., 2014; Bandala et al., 2012) and gyneco-obstetrics (Cárdenas-Rodríguez et al., 2012).

The aim of the present study was to evaluate the IHC profile of Ki67, TP53, HER2/neu, ER and PR in BCa tumors of Mexican women, since these are the most commonly used markers for diagnosis, treatment and prognosis of this carcinoma. We also explored the relation of these parameters to clinical/pathological factors in the population under study.

\section{Materials and Methods}

\section{Biological samples}

The samples of human mammary carcinomas were obtained from 48 BCa patients diagnosed at the Pathology Service of the Specialty Clinic for Women (Clínica de Especialidades de la Mujer, Secretariat of National Defense, (SEDENA) in Mexico City. Tissue samples were collected during surgery and placed in $10 \%$ formalin. The histological classification of the carcinomas as well as the evaluation of non-tumor breast lesions were made according to standard diagnostic procedures and confirmed by two pathologists.

\section{Immunohistochemistry}

Tissues were submitted to the conventional histological process for hematoxylin-eosine staining and histopathological diagnosis. Briefly, tissues were embedded in paraffin blocks to obtain 2-3 $\mu \mathrm{m}$ thick histological cuts, which were mounted on slides (ProbeOn $^{\mathrm{TM}}$ Plus Microscope Slides, Fisherband ${ }^{\circledR}$ ) and deparaffinated with heat $\left(60^{\circ} \mathrm{C}\right)$ and xylene. Subsequently, the samples were hydrated with a series of alcohols before being put in tridistilled water (high purity) and left for 5 min. Then antigens were recovered with Citrate $20 \mathrm{x}(2.5$ $\mathrm{ml}$ in $50 \mathrm{ml}$ of tridistilled water), heated to $120^{\circ} \mathrm{C}$ for 20 $\mathrm{min}$ in a pressure cooker, cooled to room temperature, and then hydrated in tris-buffered saline medium at $\mathrm{pH} 7.6$ (TBS) for $5 \mathrm{~min}$. Afterwards, the endogenous peroxidase was blocked with $3 \%$ hydrogen peroxide $\left(\mathrm{H}_{2} \mathrm{O}_{2}\right)$ for $5 \mathrm{~min}$ (at $6 \%$ dilution with methanol starting from $30 \% \mathrm{H}_{2} \mathrm{O}_{2}$ ), rinsed in TBS and left to stand for $5 \mathrm{~min}$. The samples were then mounted with a Shandon coverplate (Thermo Scientific) before applying the primary antibody (see Table 1) during 30-40 min, followed by a wash with TBS and incubation with Biotin (Dako Cytomation) during $20 \mathrm{~min}$. Slides were washed with TBS before the application of Streptavidin (Dako Cytomation) for $20 \mathrm{~min}$, then washed again before the application of a diaminobenzidine chromogene kit (DAB from Dako Cytomation) at $1.5 \mathrm{ml}$ of diluent plus two drops of aminobenzidine for $5 \mathrm{~min}$. They were then dismounted and stained with Harris hematoxylin for $5 \mathrm{sec}$ before being washed with TBS and mounted with Entellan ${ }^{\circledR}$ resin. Photographs were taken with an Olympus Camedia camera (C-5060 of 5.1 megapixels) in an optic microscope (Olympus BX50) with the 20x/0.70 $\infty / 0.17$ PLAN APO chromatic objective.

\section{Antibodies}

The immunohistochemical assay was conducted with primary (see Table 1) and secondary antibodies for recognizing human antigens. All antibodies were positive to external controls. The percentage of cells positive to $\mathrm{Ki} 67$ is about twice that found in the $\mathrm{S}$ phase. The number of vessels qualified as having CD34 corresponds to the average number of vessels displayed in 10 fields observed through a high power objective (csf 40x). HER2/neu was evaluated based on the dye affinity of the membrane. There is a table edited by DACO to estimate this parameter.

\section{Ethical aspects}

Patients read and signed the informed consent form, as required by the Ethics Commission of the National Institute of Public Health in Mexico. The current protocol was also approved by the Hospital Ethics in Research Commission (ref. no. SI-378).

\section{Statistical analysis}

The mean and standard deviation were calculated using the Chi-square test, Fisher exact test, and the KolmogorovSmirnov, Pearson and Spearman correlation. Statistical analysis was performed using SPSS v17 for Windows XP (SPSS UK, Ltd, Woking, UK). In all cases $\mathrm{p} \leq 0.05$ was regarded as significant.

\section{Results}

The average age of the patients included in the study was 58 years, with a range from 31 to 87 . The non-gynecoobstetric risk factors (Table 2) included the fact that $83.3 \%$ of the patients were over $48,61.7 \%$ had a family history of breast cancer, and $80 \%$ had a BMI greater than 25 
Table 1. Primary Antibodies (Dako Cytomation)

\begin{tabular}{lcccc}
\hline Antibody & Origin & Catalog & Type & Dilution \\
\hline Estrogenic Receptor clone 1D5 & Mo a Hu & M7047 & IgG1 & 0.145833333 \\
Progesterone Receptor clone PgR 636 & Mo a Hu & M3569 & IgG1 & 0.145833333 \\
P53 clone DO-7 & Mo a Hu & M7001 & IgG2b & 0.111111111 \\
Ki67 clone MIB-1 & Mo a Hu & M7240 & IgG1 & 0.111111111 \\
HER2/neu & Rb a Hu & A0485 & ----- & 0.388888889 \\
CD34 clone QBEnd 10 & Mo a Hu & N1632 & IgG1 & 0.180555556 \\
\hline
\end{tabular}

Table 2. Frequency of Non Gynecological and Obstetric Risk Factors for BCa

\begin{tabular}{llcc}
\hline & & Frequency & Percentage (n) \\
\hline Age (years) & $>50$ & 40 & $83.3 \%(48)$ \\
BCa Familar History & & 29 & $61.7 \%(47)$ \\
BMI (Kg/m2) & $<25$ & 9 & $20 \%(45)$ \\
& 25 a 29 & 17 & $37.8 \%(45)$ \\
& $>29$ & 19 & $42.2 \%(45)$ \\
Blood Group & $\mathrm{A}+$ & 7 & $14.9 \%(47)$ \\
& $\mathrm{B}+$ & 2 & $4.3 \%(47)$ \\
Comorbility & $\mathrm{O}+$ & 38 & $80.8 \%(47)$ \\
Non Physical Activity & & 35 & $72.9 \%(48)$ \\
Tobacco Consumption & & 46 & $95.8 \%(48)$ \\
Alcohol Consumption & & 10 & $20.8 \%(48)$ \\
Biomass Exposition & & 8 & $16.7 \%(48)$ \\
\hline
\end{tabular}

$\mathrm{kg} / \mathrm{m} 2$. The predominant blood group was $\mathrm{O}+(80.8 \%)$, followed by $\mathrm{A}+(14.9 \%)$ and $\mathrm{B}+(4.3 \%)$. In $72.9 \%$ of patients there was comorbidity, such as diabetes mellitus, HBP or some other metabolic disease. Additionally, $20.8 \%$ were smokers, $16.7 \%$ consumed alcohol, $95.8 \%$ had a sedentary lifestyle, and $14.6 \%$ reported having been exposed to biomass.

The gyneco-obstetric risk factors associated with $\mathrm{BCa}$ in the patients of the present study (Table 3 ) include the following: $52.1 \%$ had an early menarche (before turning 12), $97.9 \%$ were parous, $59.5 \%$ had their first pregnancy after turning $20,77.1 \%$ reported having been pregnant more than 3 times, and $84.8 \%$ were no longer menstruating (the mean age of menopause was 41 ). On the other hand, only $14.6 \%$ indicated using hormonal birth control.

Through IHC analysis of histopathological markers (Figure 1), immunostaining of the nucleus was observed for ER, PR, Ki67 and TP53, while HER2/neu was identified in the cell membrane and CD34 stained endothelial cells. The frequency of these markers found among the patients herein studied (Table 4) was 58.3\% positive for ER, $56.2 \%$ positive for PR, $97.9 \%$ positive for Ki67, 56.3\% negative for HER2/neu, and 56.5\% showed 1 to 20 blood vessels with CD34. Of the total number of patients, in $47.9 \%$ the left breast was affected, in $39.6 \%$ the right breast, and in $12.5 \%$ both breasts. The most frequent histological type was invasive ductal carcinoma (95.8\%), with $45.8 \%$ presenting tumor grade 3 , followed by $35.4 \%$ with grade 2 and $18.8 \%$ with grade 1 . Metastasis was found in $42.5 \%$ of patients. A poor NPI was predominant, shown by $80.4 \%$ of patients.

ER was associated with smoking $(\mathrm{p}=0.04)$, alcohol consumption $(\mathrm{p}=0.05)$, metastasis $(\mathrm{p}=0.02), \mathrm{PR}(\mathrm{p}=0.001)$, HER $2 /$ neu $(p=0.05)$ and Ki67 $(p=0.01)$. There was a tendency of association between ER and a high level of
Table 3. Frequency of Gynecological and Obstetric Risk Factors for BCa

\begin{tabular}{|c|c|c|c|}
\hline & & Frequency & Percentage (n) \\
\hline Menarche & $<12$ años & 25 & $52.1 \%(48)$ \\
\hline Oral Contraceptives & & 7 & $14.6 \%(48)$ \\
\hline Nulliparity & & 1 & $2.1 \%(48)$ \\
\hline Age of first pregnancy & $<20$ años & 17 & $40.5 \%(42)$ \\
\hline Number of pregnancies & $>3$ & 37 & $77.1 \%(48)$ \\
\hline Menopause & & 39 & $84.8 \%(46)$ \\
\hline
\end{tabular}

Table 4. Frequency of Histopathological Markers Identified in Mexican Patients Diagnosed with BCa

\begin{tabular}{lrcc}
\hline & & Frequency & Percentage (n) \\
\hline Estrogenic Receptor & Positive & 28 & $58.3 \%(48)$ \\
Progesterone Receptor & Positive & 27 & $56.2 \%(48)$ \\
TP53 & Positive & 31 & $64.6 \%(48)$ \\
Ki67 & Positive & 47 & $97.9 \%(48)$ \\
HER2/neu & Positive & 21 & $43.7 \%(48)$ \\
CD34 & $1-10$ blood vessels & 25 & $56.5 \%(45)$ \\
\multicolumn{2}{r}{$11-20$ blood vessels } & 20 & $43.5 \%(45)$ \\
\hline
\end{tabular}

triglycerides $(\mathrm{p}=0.09)$. PR was associated with smoking $(\mathrm{p}=0.009)$, alcohol consumption $(\mathrm{p}=0.05)$, metastasis $(\mathrm{p}=0.01), \operatorname{Ki} 67(\mathrm{p}=0.02)$ and urea $(\mathrm{p}=0.01)$. There was of association between HER2/neu $(\mathrm{p}=0.08)$ and creatine $(\mathrm{p}=0.09)$. The marker of Ki67 proliferation was also associated with HER2/neu ( $\mathrm{p}=0.02)$, TP53 ( $\mathrm{p}=0.001)$ and a high level of triglycerides $(\mathrm{p}=0.05)$. On the other hand, TP53 was associated with a poor NPI and showed a tendency of association with the consumption of alcohol $(\mathrm{p}=0.07)$ and with comorbidity involving HBP and some metabolic disorders $(\mathrm{p}=0.09)$. The HER2/neu marker was also associated with the number of pregnancies $(\mathrm{p}=0.005)$ and tumor size $(\mathrm{p}=0.04)$. Finally, the CD34 marker was related to smoking $(\mathrm{p}=0.05)$ and showed a tendency of association with a sedentary lifestyle $(\mathrm{p}=0.09)$ and a high level of triglycerides $(\mathrm{p}=0.09)$.

The condition of triple negative (ER-/PR-/HER2/ neu-) showed an association with smoking ( $\mathrm{p}=0.02)$, consumption of alcohol ( $\mathrm{p}=0.006)$, exposure to biomass $(\mathrm{p}=0.04)$, number of pregnancies $(\mathrm{p}=0.04)$, metastasis $(\mathrm{p}=0.05)$, and a poor NPI $(\mathrm{p}=0.003)$, as well as a tendency of association with triglycerides $(\mathrm{p}=0.09)$. On the other hand, the condition of triple positive (ER+/PR+/HER2/ neu+) was associated with histological type $(\mathrm{p}=0.007)$, tumor size $(\mathrm{p}=0.03)$, and high cholesterol $(\mathrm{p}=0.02)$. Tumor size was associated with a family history of $\mathrm{BCa}(\mathrm{p}=0.005)$, histological type $(\mathrm{p}=0.01)$, presence of comorbidity $(\mathrm{p}=0.02)$, the age of the first pregnancy $(\mathrm{p}=0.02)$, high cholesterol $(\mathrm{p}=0.05)$ and blood group $(\mathrm{p}=0.04)$, and there was a tendency to association with 

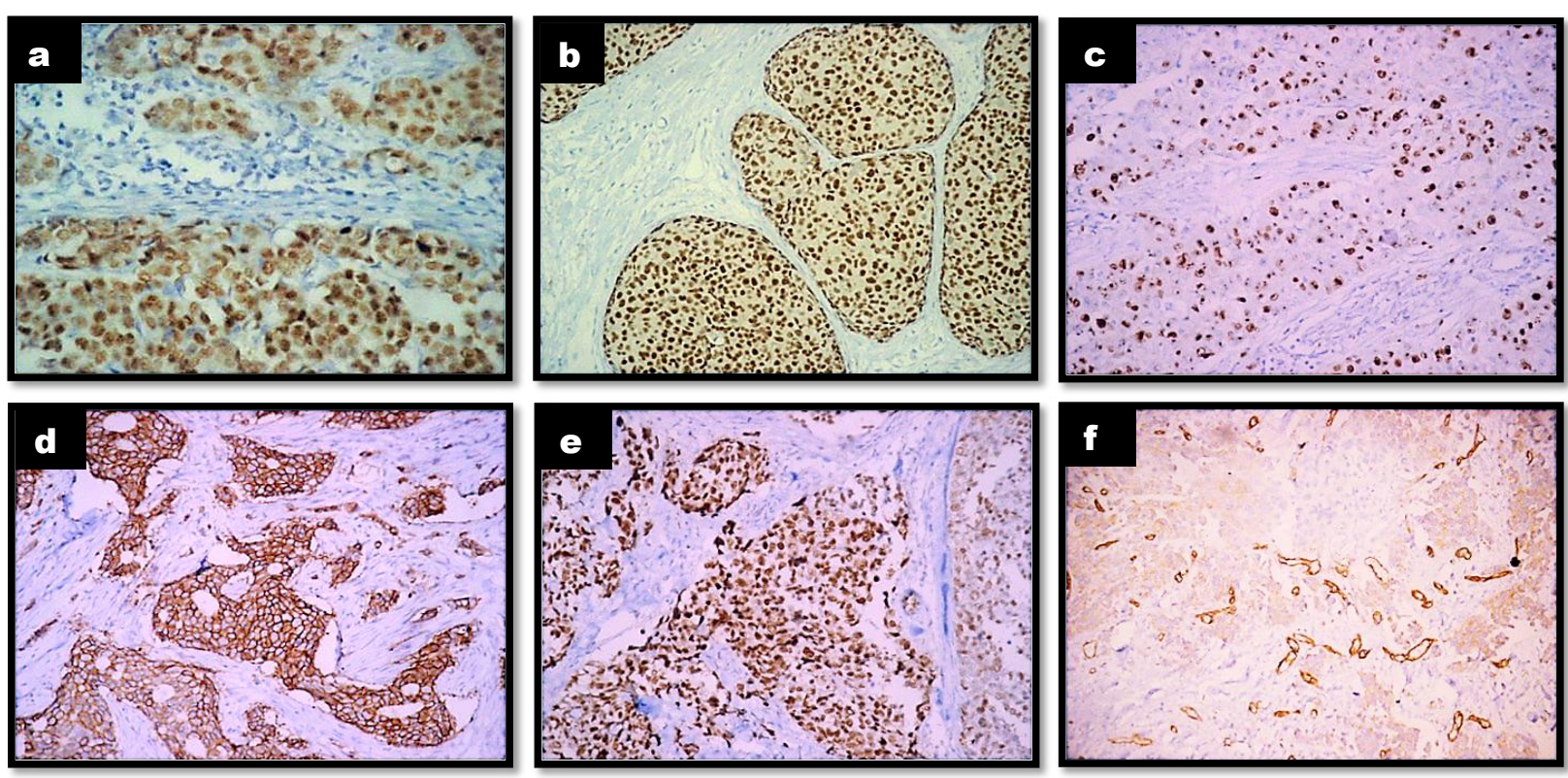

Figure 1. Histopathological Markers Identified in Biopsies of Patients with BCa. a) Estrogenic receptor, b) Progesterone receptor, c) Ki67, d) HER2/neu, e) TP53 and f) CD44

a high level of triglycerides $(\mathrm{p}=0.07)$. Histological type was associated with the BMI $(\mathrm{p}=0.004)$, high cholesterol $(\mathrm{p}=0.05)$ and the $\mathrm{O}+$ blood group $(\mathrm{p}=0.0001)$, and there was a tendency to association with menopause $(\mathrm{p}=0.06)$ and alcohol consumption $(\mathrm{p}=0.07)$. Histological grade was associated with alcohol consumption $(\mathrm{p}=0.03)$ and the tumor stage $(\mathrm{TNM})(\mathrm{p}=0.02)$. A poor NPI was associated with metastasis $(0.001)$, tumor stage (TNM) $(0.02)$, histological grade $(\mathrm{p}=0.001)$ and the number of pregnancies $(\mathrm{p}=0.02)$. Additionally, the tumor stage (TNM) was associated with the BMI ( $\mathrm{p}=0.01)$. Metastasis showed an association with menopause $(\mathrm{p}=0.01)$ and smoking $(p=0.007)$. Finally, the blood group of patients was associated with their BMI ( $\mathrm{p}=0.005)$, family history of $\mathrm{BCa}(\mathrm{p}=0.001)$, age of menarche $(\mathrm{p}=0.02)$, and age of menopause $(\mathrm{p}=0.001)$.

An analysis was made of the correlations between each of histopathological markers considered herein, including ER, PR, TP53, Ki67 and HER2/neu, and also between these parameters and other risk factors. With respect to $\mathrm{ER}$, a correlation was found with $\mathrm{PR}(\mathrm{p}=0.0001$; rho $=0.822)$, Ki67 ( $\mathrm{p}=0.005$; rho $=-0.400)$, a high level of triglycerides $(\mathrm{p}=0.05 ; \mathrm{rho}=0.521)$ and high cholesterol $(p=0.07 ;$ rho $=0.498)$. PR showed a correlation with Ki67 $(\mathrm{p}=0.001 ;$ rho $=-0.463)$, a high level of triglycerides $(\mathrm{p}=0.003$; rho $=0.727)$ and high cholesterol $(\mathrm{p}=0.003$; $\mathrm{rho}=0.727)$. TP53 was associated with the age of the first pregnancy $(\mathrm{p}=0.01 ; \mathrm{rho}=0.378)$. Ki67 was related to the age at which $\mathrm{BCa}$ was diagnosed $(\mathrm{p}=0.02$; rho= $-0.326)$, the age of menopause $(\mathrm{p}=0.01 ; \mathrm{rho}=0.360)$, and a high level of triglycerides $(\mathrm{p}=0.05$; rho $=-0.525)$. TP53 also demonstrated a tendency to correlation with high cholesterol $(\mathrm{p}=0.09$; rho $=-0.470)$. Finally, CD34 was correlated with high cholesterol $(\mathrm{p}=0.05$; rho $=0.535)$.

\section{Discussion}

The current contribution explores protein expression in $\mathrm{BCa}$ tumor biopsies taken from 48 Mexican women. The following histological markers were explored: ER, PR, HER2/neu, Ki67, TP53 and CD34. Analysis was carried out to find the possible relation of the expression of each protein with the others and with socio-demographic and gyneco-obstetric factors.

The average age of the Mexican women herein diagnosed with BCa (over 48) coincides with reports for Mexico and other Latin American countries by various authors (Rummel et al., 2012; Keyhani et al., 2013; Justo et al., 2013; Villarreal-Garza et al., 2013; FlorianoSánchez et al., 2014; Ji et al., 2014; Doval et al., 2015). For these patients, the frequency of early menarche, the age of the first pregnancy, the number of pregnancies, early menopause, and the history of taking oral birth control are similar to that reported by Gates et al. (2012) and by other authors (Cardenas-Rodriguez et al., 2012; Amadou et al., 2014; Floriano-Sanchez et al., 2014; Doval et al., 2015). Neither a family history of BCa or nulliparity were common in the patients of the current contribution. The scarcity of nulliparous women in the study is probably due to cultural factors that lead most women in Mexico to be multiparous.

Regarding lifestyle factors, sedentariness, overweight/ obesity and comorbidities were very frequent in the patients herein analyzed, while smoking and alcohol consumption were not. These data are congruent with those reported by other authors (Gates et al., 2012; Floriano-Sanchez et al., 2014; Amadou et al., 2014; Maschio et al., 2014).

The $\mathrm{O}+$ blood group predominated, followed by group A+, also coinciding with that reported in other studies of $\mathrm{BCa}$ in Hispanic populations. However, studies from Caucasian populations report that group $\mathrm{A}+$ is more common for BCa patients. This is easily explained by the fact that $\mathrm{O}+$ is the most common blood group in the Hispanic population, whereas the $\mathrm{A}+$ group is more frequent in the Caucasian population. Nevertheless, there are contradictory reports on this question in regard to BCa (Gates et al., 2012; Zhang et al., 2014; Abobaker 
and Kamil, 2014).

The detection of a $\mathrm{BCa}$ tumor was more frequent in the left breast, similar to that reported by other authors (Keyhani et al., 2013; Ji et al., 2014). The most common histological type was invasive ductal carcinoma, also similar to many other reports (Rummel et al., 2012; Cardenas-Rodríguez et al., 2012; Keyhani et al., 2013; Petric et al., 2014). Stage 3 was the most commonly detected tumor stage in the present study, which coincides with some studies (e.g., Petric et al., 2014) but differs from others that have found a greater presence of stage 1 or 2 (Rummel et al., 2012; Keyhani et al., 2013; Justo et al., 2013; Ji et al., 2014).

A poor NPI was determined in the majority of patients herein studied, coinciding with other reports on the Mexican population (e.g., Bandala et al., 2012) but contrasting with studies conducted in European populations, where a good NPI was most commonly identified (e.g., Bates et al., 2014). Metastasis at the moment of diagnosis was $10 \%$ more frequent in the present study than what Cardenas-Rodriguez et al. (2012) or Maschio et al. (2014) reported, and similar to that reported by Leon-Hernández et al. (2014).

The frequency of ER+ in the current sample of $\mathrm{BCa}$ patients was lower than that reported by several authors: $12.9 \%$ lower versus Keyhani et al. (2013), 19.7\% versus Rummel et al. (2012), 4.7\% versus Maschio et al. (2014), $3.9 \%$ versus Doval et al. (2015), and $13.7 \%$ versus Ji et al. (2014). Meanwhile, the frequency of PR+ presently detected was lower than that reported by several authors (10.8\% versus Gates et al., 2012; 8.5\% versus Keyhani et al., 2013; 16.9\% versus Ji et al., 2014) and higher than that reported by some others (1.2\% versus Maschio et al., 2014; 3\% versus Doval et al., 2015). Pervaiz et al. (2015) found an association between ER+ and histological grade, while PR+ was associated both with this factor and tumor size. Floriano-Sanchez et al. (2014) found a significant relation of ER+ with alcoholism and PR+.

HER2/neu was positive in $43.7 \%$ of cases herein studied, higher than that reported by various authors (24.7\% higher versus Gates et al., 2012; $21.2 \%$ versus Keyhani et al., 2013; 20.7\% versus Doval et al., 2015; $9.1 \%$ versus Ji et al., 2014, which was identified by FISH), but lower than that found by others $(9.6 \%$ versus Rummel et al., 2012; $13.3 \%$ versus Maschio et al., 2014). A positive HER2/neu was related to the number of pregnancies, $\mathrm{PR}+$ and the tumor size, coinciding with that observed by Keyhani et al. (2013), while Ji et al. (2014) found a relation of HER2/neu with histological grade, ER+, PR+ and TP53.

The condition of triple negative (ER-/PR-/HER2/neu-) showed an association with smoking, alcohol consumption, exposure to biomass, number of pregnancies, and with malignancy parameters like metastasis, coinciding with the results reported by Leon-Hernandez et al. (2014). An association was also found presently between this triple negative condition and a poor NPI. Dent et al. (2007) reported that triple negative patients had a lower survival rate, which was associated with histological grade 3 and a greater tumor size. On the other hand, Doval et al. (2015) found an association between tumor grade, histological type, tumor stage, early menopause, and women under
50 years of age. Kurshumliu et al. (2014) observed that a poor NPI was related to overexpression of HER2/neu.

In the current contribution the condition of triple positive $(\mathrm{ER}+/ \mathrm{PR}+/ \mathrm{HER} 2 / \mathrm{neu}+)$ was associated with histological type, similar to the finding of Zheng et al. (2015), as well as with tumor size and high cholesterol $(\mathrm{p}=0.02) . \mathrm{Ki} 67$ was expressed in almost all patients studied presently $(97.9 \%)$, similar to other reports (Keyhani et al., 2013; Ji et al., 2014; Petric et al., 2014; Maschio et al., 2014). However, the majority of the aforementioned authors utilized low/moderate/high as the classification of expression for this marker, whereas in the present study the analysis of Ki67 expression was not carried out in this way. Ki67 expression was associated with HER2/neu, similar to what Keyhani et al. (2013) and Ji et al. (2014) reported, and was also related to $\mathrm{ER}+, \mathrm{PR}+$ and a high level of triglycerides.

The expression of TP53 in the current contribution was greater than that reported by two authors $(31.3 \%$ greater versus Keyhani et al., 2013; 9.6\% versus Maschio et al., 2014) and similar to the results of Cárdenas-Rodriguez et al. (2012). The expression of TP53 found presently was associated with a poor NPI and Ki67+, the latter coinciding with the findings of Keyhani et al. (2013), who also mentioned an association between tumor grade and CD34 expression.

Regarding CD34, we evaluated this parameter as 1-10 vessels or 11-20 vessels, whereas other authors classified it as low/moderate/high. The present results show a greater frequency for 1-10 vessels, which coincides with Keyhani et al. (2013), who found that a lower expression was more frequent. CD34 is important because of its demonstrated relation to other angiogenic factors (VEGF and HIF-1). Moreover, it has proven to be an important factor in $\mathrm{BCa}$ progression and its abundance in breast tumors has prognostic and predictive value (Maschio et al., 2014). CD34 was herein associated with smoking and a high level of cholesterol. On the other hand, Keyhani et al. (2013) found a relation between CD34 and HER2/ neu in an Iranian population, and Maschio et al. (2014) reported that this marker was related to hormonal therapy, ER, HER2/neu, Ki67, radiotherapy and metastasis in a Brazilian population.

Although the current analysis had some limitations, such as a possible inherent bias due to the retrospective nature of the analysis, the evidence herein presented unequivocally establishes that the histopathological markers of ER, PR, HER2/neu, TP53 and Ki67 cannot be omitted when analyzing $\mathrm{BCa}$ patients, since these are closely linked to diagnosis, prognosis and treatment, as well as being predictive in their relation with risk factors for $\mathrm{BCa}$.

\section{References}

Amadou A, Torres-Mejía G, Hainaut P, Romieu I (2014). Breast cancer in Latin America: global burden, patterns, and risk factors. Salud Publica Mex, 56, 547-54

Abovaker S Kamil M (2014). Incidence of breast cancer in a primary hospital in relation to $\mathrm{ABO}$ blood groups system. $J$ Med and Bioeng, 3, 74-7. 
Anaya-Ruiz M, Vallejo-Ruiz V, Flores-Mendoza L, Perez-Santos M (2014). Female breast cancer incidence and mortality in Mexico, 2000-2010. Asian Pac J Cancer Prev, 15, 1477-9.

Bandala C, Floriano-Sánchez E, Cárdenas-Rodríguez N, et al (2012). RNA expression of cytochrome P450 in Mexican women with breast cancer. Asian Pac J Cancer Prev, 13, 2647-53.

Bates T, Evans T, Lagord C, Monypenny I, et al (2014). A population based study of variations in operation rates for breast cancer, of comorbidity and prognosis at diagnosis: failure to operate for early breast cancer in older women. Eur J Surg Oncol, 40, 1230-6.

Cárdenas-Rodríguez N, Lara-Padilla E, Bandala C, et al (2012). CYP2W1, CYP4F11 and CYP8A1 polymorphisms and interaction of CYP2W1 genotypes with risk factors in Mexican women with breast cancer. Asian Pac J Cancer Prev, 13, 837-46

Chavarri-Guerra Y, Villarreal-Garza C, Liedke P, et al (2012). Breast cancer in Mexico: a growing challenge to health and the health system, Lancet Oncol, 13, 335-46.

Cheang MC, Chia SK, Voduc D, Gao D, et al (2009) Ki67 index, HER2 status, and prognosis of patients with luminal B breast cancer. J Natl Cancer Inst, 101,736-50.

Cuzick J, Dowsett M, Pineda S, et al (2011). Prognostic value of a combined estrogen receptor, progesterone receptor, $\mathrm{Ki} 67$, and human epidermal growth factor receptor 2 immunohistochemical score and comparison with the Genomic Health recurrence score in early breast cancer. $J$ Clin Oncol, 29, 4273-8.

De Azambuja E, Cardoso F, de Castro G Jr, et al (2007). Ki67 as prognostic marker in early breast cancer: a meta-analysis of published studies involving 12,155 patients. Br J Cancer, 96,1504-13.

Dent R, Trudeau M, Pritchard KI, et al (2007). Triple-negative breast cancer: clinical features and patterns of recurrence. Clin Cancer Res, 13, 4429-34

Dirección General de Información en Salud (DGIS). Base de datos de defunciones 1979-2009. Sistema Nacional de Información en Salud (SINAIS). Available at: <http://www. sinais.salud.gob.mx>. salud.gob.mx

Doval DC1, Sharma A,Sinha R, etal(2015).Immunohistochemical profile of breast cancer patients at a tertiary care hospital in New Delhi, India. Asian Pac J Cancer Prev, 16, 4959-64.

Elledge RM, Fuqua SA, Clark GM, et al (1993). Prognostic significance of $\mathrm{p} 53$ gene alterations in node-negative breast cancer. Breast Cancer Res Treat, 26, 225-35.

Fitzmaurice C, Dicker D, Pain A, et al (2015). The global burden of cancer 2013. JAMA Oncol, 1, 505-27.

Floriano-Sanchez E, Rodriguez NC, Bandala C, et al (2014). CYP3A4 expression in breast cancer and its association with risk factors in Mexican women. Asian Pac J Cancer Prev, 15, 3805-9.

Frebourg T, Friend SH (1993). The importance of p53 gene alterations in human cancer: is there more than circumstantial evidence? J Natl Cancer Inst, 85, 1554-57.

Gates MA, Xu M, Chen WY, Kraft P, Hankinson SE (2012). Wolpin BM. ABO blood group and breast cancer incidence and survival. Int J Cancer, 130, 2129-37.

Hsiao YH, Siddiqui S, Man YG (2010). Dual use of a single Wilms' tumor 1 immunohistochemistry in evaluation of ovarian tumors: a preliminary study of 20 cases. J Cancer, 13, 93-7.

Ji Y, Sheng L, Du X, Qiu G, Chen B, Wang X (2014). Clinicopathological variables predicting HER-2 gene status in immunohistochemistry-equivocal (2+) invasive breast cancer. J Thorac Dis, 6, 896-904.

Justo N, Wilking N, Jönsson B, et al (2013). A review of breast cancer care and outcomes in Latin America. Oncologist, 18, 248-56.

Keyhani E, Muhammadnejad A, Behjati F, Sirati F (2013). Pazhoomand. Angiogenesis markers in breast cancer-potentially useful tools for priority setting of anti-angiogenic agents. Asian Pac J Cancer Prev, 14, 7651-6.

Kurshumliu F, Gashi-Luci L, Kadare S, Alimehmeti M and Gozalan U (2014). Classification of patients with breast cancer according to Nottingham Prognostic Index highlights significant differences in immunohistochemical marker expression. World J Surg Oncol, 12, 1-5.

Lane DP (1992). Cancer. p53, guardian of the genome. Nature, 358, $15-6$.

Leon-Hernandez SR, Padilla EL, Algara AC, et al (2014). Relation of alcohol/tobacco use with metastasis, hormonal (estrogen and progesterone) receptor status and c-erbB2 protein in mammary ductal carcinoma. Asian Pac J Cancer Prev, 15, 5709-14.

Maschio LB, Madallozo BB, Capellasso BA, et al (2014). Immunohistochemical investigation of the angiogenic proteins VEGF, HIF- $1 \alpha$ and CD34 in invasive ductal carcinoma of the breast. Acta Histochem, 116, 148-57.

Nigro JM, Baker SJ, Preisinger AC, et al (1989). Mutations in the p53 gene occur in diverse human tumour types. Nature, 342, 705-8.

Niikura N, Iwamoto T, Masuda S, et al (2012). Immunohistochemical Ki67 labeling index has similar proliferation predictive power to various gene signatures in breast cancer. Cancer Sci, 103, 1508-12.

Ohno S, Chow LW, Sato N, et al (2013). Randomized trial of preoperative docetaxel with or without capecitabine after 4 cycles of 5-fluorouracil- epirubicin-cyclophosphamide (FEC) in early-stage breast cancer: exploratory analyses identify Ki67 as a predictive biomarker for response to neoadjuvant chemotherapy. Breast Cancer Res Treat, 142, 69-80.

Perez-Santos JL, Anaya-Ruiz M (2013). Mexican breast cancer research output, 2003-2012. Asian Pac J Cancer Prev, 14, 5921-3.

Petric M, Martinez S, Acevedo F, et al (2014). Correlation between Ki67 and histological grade in breast cancer patients treated with preoperative chemotherapy. Asian Pac J Cancer Prev, 15, 10277-80

Pervaiz F, Rehmani S, Majid S, Anwar H (2015). Evaluation of Hormone Receptor Status (ER/PR/HER2-neu) in Breast Cancer in Pakistan. J Pak Med Assoc, 65, 747-52.

Rummel S, Shriver CD, Ellsworth RE (2012). Relationships between the ABO blood group SNP rs505922 and breast cancer phenotypes: a genotype-phenotype correlation study. BMC Med Genet, 13, 41.

Seshie B, Adu-Aryee NA, Dedey F, Calys-Tagoe B, CleggLamptey JN (2015). A retrospective analysis of breast cancer subtype based on ER/PR and HER2 status in Ghanaian patients at the Korle Bu Teaching Hospital, Ghana. BMC Clin Pathol, 15, 14.

Shui R, Yu B, Bi R, Yang F, Yang W (2015). An interobserver reproducibility analysis of Ki67 visual assessment in breast cancer. PLoS One, 10, 125131.

Tirona MT, Sehgal R, Ballester O (2010). Prevention of breast cancer (part I): Epidemiology, risk factors, and risk assessment tools. Cancer Invest, 28, 743-50.

Thor AD, Moore DH II, Edgerton SM, et al (1992). Accumulation of p53 tumor suppressor gene protein: an independent marker of prognosis in breast cancers. J Natl Cancer Inst, 84, 845-55.

Thorlacius S, Börresen AL, Eyfjörd JE (1993). Somatic p53 mutations in human breast carcinomas in an Icelandic 

population: a prognostic factor. Cancer Res, 53, 1637-41.

Villarreal-Garza C, Aguila C, Magallanes-Hoyos MC, et al (2013). Breast cancer in young women in Latin America: an unmet, growing burden. Oncologist, 18, 1298-306.

von Minckwitz G, Schmitt WD, Loibl S, Muller BM, Blohmer JU, Sinn BV, et al (2013). Ki67 measured after neoadjuvant chemotherapy for primary breast cancer. Clin Cancer Res: Off J Am Assoc Cancer Res, 19, 4521-31.

Yerushalmi R, Woods R, Ravdin PM, Hayes MM, Gelmon KA (2010). Ki67 in breast cancer: prognostic and predictive potential. Lancet Oncol, 11, 174-83.

Zhang BL, He N, Huang YB, Song FJ, Chen KX (2014). ABO blood groups and risk of cancer: a systematic review and meta-analysis. Asian Pac J Cancer Prev, 15, 4643-50.

Zheng,YZ, Wang L, Hu X, Shao ZM (2015). Effect of tumor size on breast cancer-specific survival stratified by joint hormone receptor status in a SEER population-based study. Oncotarget, 2015. www.impactjournals.com/oncotarget. 